\section{Impact of climate change}

SIR - I should like to comment on your report headed "Developing countries dispute use of figures on climate change impacts" (Nature 376, 374; 1995) about a meeting of Working Group III of the Intergovernmental Panel on Climate Change (IPCC).

The terms of reference approved by governments for the working group require it to assess the socio-economic literature related to, among other topics, climate change damage, mitigation costs and applicability of cost-benefit analysis to analysis of climate change. The story implies that Working Group III "put a value on a death in a developed country". This statement is incorrect. The figures cited in the story are drawn from the peer-reviewed literature, not calculations by Working Group III, which has not and will not carry out new calculations.

The article also refers to "damage caused by a doubling in carbon dioxide concentrations (1.5-2 per cent)". The working group report points out that the literature contains only a few estimates of climate change damage. The values cited in the story are qualified as best guess' central estimates for a doubled carbon dioxide concentration and equilibrium climate change, on an economy with the same structure as the present world economy.

The damage cost estimates in the literature include a value for the increased risk of mortality due to climate change. Studies that estimate the damage caused by climate change at a regional level have used estimates of the value of a statistical life for the different regions. Those values are substantially higher for industrialized regions than for developing regions. The Working Group III report also describes the effect of adopting a uniform value of a statistical life for all regions. Finally, the report also points out that, in formulating climate change policy, decision-makers may well wish to assign different equity weights to the value of various damages, including the risk of mortality, in different regions.

The working group's draft 'summary for policy makers' presents two estimates of mitigation costs for greenhouse gases. First, it says that energy efficiency of perhaps 10 to 30 per cent of current consumption can be realized at negative to slightly positive cost. It also points out that estimates of the cost of stabilizing carbon dioxide emissions at 1990 levels for several decades beyond 2000 in OECD countries vary widely, but 'topdown' models project that they may ultimately exceed 1 to 2 per cent of gross domestic product.

When your story says that the "IPCC committee had calculated that slowing down global warming could be more expensive than merely paying for the damage caused", it is apparently comparing the 'best guess' estimate of damages for a doubled carbon dioxide equilibrium climate with the 'top-down' model estimate of the cost of stabilizing carbon dioxide emissions in OECD countries for several decades beyond 2000 . The costs and damages compared relate to completely different situations. The comparison is simply not valid.

I believe that the draft report clearly recognizes the limitations of benefit-cost analysis for climate change policy. The inference that the Working Group III draft report presents a cost-benefit analysis that suggests that little need be done to slow warming is completely inaccurate. James P. Bruce

(Co-Chair Working Group III)

Intergovernmental Panel

on Climate Change,

145 King Street West, Suite 1002,

Toronto, Ontario M5H 3XS,

Canada

SIR - Your news item reports me as saying that developing nations have so far failed to propose a single workable alternative to Western cost-benefit models.

In fact, what I told your reporter was that the available literature does not contain information on methods of putting a value on life other than what is reported by Working Group III of the Intergovernmental Panel on Climate Change (IPCC); almost all the available literature on the subject is to be found in the developed world.

\section{N. Sundaraman}

(Secretary to the IPCC)

IPCC Secretariat, WMO,

41 Av. Giuseppe-Motta,

CP No. 2300,

1211 Geneva 2,

Switzerland

\section{Hidden meaning}

SIR - I was amused to see the word "tucaresol" "1,2 used as the name of a drug with potential in the treatment of chronic infectious disease and cancer.

The British authors unconsciously make a pun in Japanese.

In Japanese, tucare means "fatigue", and sol means "shave" (or, in the case of tol means "remove"). "Tucaresol" therefore means "reduce fatigue".

Tomoyuki Hisa

Department of Dermatology,

Osaka City University Medical School,

1-5-7 Asahimachi, Abeno-ku,

Osaka 545, Japan

1. Rhodes, J. Nature 377, 71-75 (1995)

2. Shearer, G. M. Nature 377, 16-17 (1995).

\section{Italian reforms}

SIR - There has been much discussion, both in Italy and abroad, about the way in which candidates are appointed to university posts in Italy.

Good candidates are often passed over, and recourse to the law is unproductive because of the delays and the costs involved. The minister for universities and research, Professor Giorgio Salvini, is reported to be preparing reforms, but many of us have little confidence that they will be successful because they do not take sufficient account of the principal issues.

Italian universities need to share the standards of efficiency, honesty and justice demanded by international competition and Italy's cultural tradition. The chief problem with Salvini's proposed law is that it entrusts the enforcement of the new rules to the same people who are responsible for the present state of Italian universities.

In particular, as I understand it, the proposed reforms ignore the plight of those who have already been passed over; this is damaging to the universities and discouraging to the new generation. The new law also provides for about 50 per cent more certifications than the number of positions available, which will be valid for two years after the job competition has taken place, giving those already certified an advantage.

There are many other grave defects in the proposed reforms. What Italy needs, by contrast, is a system in which both the duties of professors at different career levels and promotion from one level to another are decided honestly and on merit alone. Changing the details of the present system will not remedy its glaring faults.

\section{Salvatore Sorriso}

Università di Perugia,

via Elce di sotto 10 ,

06100 Perugia, Italy

\section{Wrong place}

SIR - I was concerned to read in your article "More precise solar-limb lightbending" (Nature 377, 11; 1995) that Eddington and his associate Crommelin had taken themselves off to the western Pacific to observe the total solar eclipse of 29 May 1919. Hitherto I was under the impression that Eddington had gone to Principe off the West African coast, and Crommelin had gone to Sobral in Brazil.

If your article is correct then there are grave implications for the gravitational bending of light and I am surprised that the standard errors of the measurements were so small.

Colin Davies

11 Lucan Road,

Aigburth, Liverpool L17 OBR, UK 